\title{
The Development of Sensorimotor Cognition in Common Ravens (Corvus corax) and its Comparative Evolution
}

\author{
Ivo Jacobs*, Can Kabadayi, and Mathias Osvath
}

Department of Cognitive Science, Lund University, Sweden

*Corresponding author (Email: ivo.jacobs@lucs.lu.se)

Citation - Jacobs, I., Kabadayi, C., \& Osvath, M. (2019). The development of sensorimotor cognition in common ravens (Corvus corax) and its comparative evolution. Animal Behavior and Cognition, 6(3), 194-212. https://doi.org/10.26451/abc.06.03.04.2019

\begin{abstract}
Evolution involves developmental change. Species comparisons play an important role in comparative cognition because they can uncover common patterns and shared principles in cognitive evolution. Developmental studies reveal foundational elements of cognitive abilities and how they are constructed and integrated. Sensorimotor cognition is such a key element that forms the foundation for later-developing cognitive skills, yet little is known about its development in animals. This study uses 37 behaviors and tasks to investigate the development of Piagetian sensorimotor abilities in five young ravens (Corvus corax) from ages two to eleven weeks. Their developmental pattern largely mirrored that of twelve other bird and mammal species, albeit at a markedly accelerated rate. They reached the final sensorimotor stage, which to date has been shown only in great apes. The onset and sequence of sensorimotor development was identical for all species. Absolute number of neurons in the pallium and rest of brain was associated with achieving a higher stage across these species. This was not the case for absolute or relative brain mass, or number of neurons in the cerebellum or whole brain. We discuss the independent evolution of sensorimotor cognition and the importance of developmental pace and pattern therein. These findings show that the study of sensorimotor development is a useful tool for comparative cognition research.
\end{abstract}

Keywords - Cognitive development, Sensorimotor cognition, Evolution of cognition, Heterochrony, Common raven

A major challenge in comparative psychology lies in making reliable comparisons among species, which becomes particularly difficult when they differ in such respects as morphology and ecology. These challenges become more pronounced with the discovery of complex cognition in taxa phylogenetically distant from one another. However, studying development may reveal how fully functional cognitive abilities are composed of diverse elements and their interactions, which different taxa share to various degrees. Developmental studies are thus an important tool in comparative cognition. To date, however, relatively little research has been done on cognitive development across species.

Tinbergen (1963) added ontogeny (development) to the other three major questions one must answer to get a complete understanding of a behavior: causation (mechanism), survival value (fitness), and evolution (phylogeny). Respectively, these questions ask how a behavior develops, how it works, what it evolved for, and how it evolved. All four questions are rarely answered, and the developmental perspective is especially lagging behind (Bateson \& Laland, 2013). The development of human cognition has been a fruitful research area for a long time - with Darwin's (1877) study of his own children as a notable early example - but less is known about cognitive development in other species, despite the fact that it also evoked interest in the early days of comparative cognition (e.g., Mills, 1898; Morgan, 1896). 


\section{Sensorimotor Cognition and Development}

Complex cognitive abilities such as behavioral flexibility, means-end understanding, inhibitory control and cultural learning have been found in distantly related species, ranging from apes and dolphins to parrots and corvids. However, establishing the extent of similarity between them calls for studies of underlying mechanisms, along with their developmental pace and pattern (Gómez, 2004; Osvath, Kabadayi, \& Jacobs, 2014; Parker \& McKinney, 1999; Rosati, Wobber, Hughes, \& Santos, 2014; Wobber, Herrmann, Hare, Wrangham, \& Tomasello, 2014). One such foundational element that can be studied developmentally is sensorimotor cognition, which involves the integration of an agent's sensory and motor systems and allows for the adaptation to and manipulation of its environment (Melin, Young, Mosdossy, \& Fedigan, 2014; Müller, 2009; Parker \& McKinney, 1999). This view has its roots in the work of Piaget (1951, 1952, 1954), who formulated an influential theory of cognitive development in children. It combines biological and psychological development, which forms the basis of a stepwise cognitive sequence leading to symbolic, logical, and rational thought. Piaget viewed development as progressive transformation, differentiation, and integration of behavioral and cognitive processes. Sensorimotor intelligence consists of coordinated action that is not habitual or based on perceptible properties of objects or events (Carey, Zaitchik, \& Bascandziev, 2015; Doré \& Dumas, 1987; Müller, 2009; Spelke, 1991). The child actively constructs it through its sensorimotor interactions with the world, which form a foundation for later-developing and more complex cognitive abilities

Piaget divided development into four periods, starting with the six-stage sensorimotor period from birth to two years of age. Progression through each stage reflects increasing complexity, coordination, intentionality, functionality, voluntary control, affordance learning, and motor-pattern variability (Doré \& Dumas, 1987; Lourenço, 2016; Parker \& McKinney, 1999). This division into stages is not meant to be absolute; it is more descriptive than explanatory. Although many factors may influence performance and age of acquisition, they are essential parts of these cognitive abilities and cannot be separated from them. Furthermore, Piaget regarded age of acquisition as an indicator-not criterion —of developmental stages, and instead focused on their order and structure to identify universal aspects (Lourenço \& Machado, 1996; Müller, 2009).

In Piagetian theory, stage one of the sensorimotor period starts at birth and encompasses reflexes. Primary circular reactions are repeated behaviors towards one's own body - such as thumb sucking representing the second stage. This develops into the secondary circular reactions of the third stage, where the infant repeats behaviors towards her environment, such as shaking an object to reproduce a sound. Piaget claimed that the first truly intelligent behavior occurs in the fourth stage, when the infant coordinates acquired behaviors in a goal-oriented manner - for example, obtaining an out-of-reach toy by pulling a string attached to it. The fifth stage is typified by tertiary circular reactions, which are new means to achieve ends. The child experiments with physical principles for their own sake, as exemplified by dropping objects from different heights to test the outcome. True representation arises in the sixth stage, wherein the infant can solve problems mentally before acting them out. This marks the end of the sensorimotor period, because the infant starts relying on symbolic representation - at first in the form of mental images - characteristic of the subsequent period (Doré \& Dumas, 1987; Gómez, 2004; Müller, 2009; Parker \& McKinney, 1999).

Piagetian theory can and has been criticized on several grounds, mainly because performance on its tests (1) requires deliberate action that may be unreliable; (2) is determined by a mixture of cognitive abilities; and (3) is confounded by non-controlled factors (see Discussion). Nonetheless, sensorimotor cognition plays a key role in contemporary theories of embodied, situated and extended cognition (e.g., Clark, 2011; Keijzer, 2017; Thelen, Schoner, Scheier, \& Smith, 2001; Wilson, 2002), and Piaget's sensorimotor intelligence series in particular is well accepted (Doré \& Dumas, 1987; Gelman \& Baillargeon, 1983; Gómez, 2004; Lourenço, 2016; Lourenço \& Machado, 1996; Pepperberg, 2002; Vauclair, 2012). Piaget's developmental methods can be successfully applied without a strict adherence to his theoretical standpoints. The Piagetian sensorimotor testing series is a fruitful area for comparative cognition because it involves spontaneous non-verbal behaviors that are ecologically relevant for a wide 
variety of species. So far, it has been investigated in twelve mammal and bird species: yellow-crowned parakeets (Cyanoramphus auriceps; Funk, 2002), grey wolves (Canis lupus lupus; Fiset, NadeauMarchand, \& Hall, 2014), domestic cats (Felis silvestris catus; Dumas \& Doré, 1991), tufted capuchins (Sapajus apella; Spinozzi, 1989), Northern plains gray langurs (Semnopithecus entellus; ChevalierSkolnikoff, 1982), stumptail macaques (Macaca arctoides; Chevalier-Skolnikoff, 1976, 1977; Parker, 1977), long-tailed macaques (M. fascicularis; Potí, 1989), Japanese macaques (M. fuscata; Antinucci, Spinozzi, Visalberghi, \& Volterra, 1982; Potí, 1989), Bornean orangutans (Pongo pygmaeus; ChevalierSkolnikoff, 1982, 1983), Western gorillas (Gorilla gorilla; Chevalier-Skolnikoff, 1976, 1977, 1982; Redshaw, 1978; Spinozzi \& Natale, 1989), chimpanzees (Pan troglodytes; Chevalier-Skolnikoff, 1982; Hallock \& Worobey, 1984; Potí \& Spinozzi, 1994), and humans (Homo sapiens sapiens; Piaget, 1952).

The Piagetian sensorimotor series has a notably anthropocentric focus, with adult human cognition as the endpoint. The relevant tests are often easier to adapt to species resembling humans with respect to anatomy, ecology, predisposition, motivation, and locomotion. It is therefore no surprise that primates have been tested most (Doré \& Dumas, 1987; Gómez, 2004; Parker \& McKinney, 1999; Pepperberg, 2002; Vauclair, 2012). This does not mean, however, that more distantly related species are unsuitable - only that the tests must be adapted to enable comparison. For example, Funk (1996a, 1996b, 2002; Funk \& Matteson, 2004) investigated the development of yellow-crowned parakeets (Cyanoramphus auriceps) in several Piagetian domains and found consistent individual performance and a development pattern similar to that of human infants. Although the parakeets developed much faster, the precise timing of their development, resulting from various performance factors, is relatively unimportant. The main questions are in what order a species reaches each stage and what the highest achieved stage is. Species-specific confounds are mitigated by using several tests for each stage (Pepperberg, 2002).

\section{Comparative Neuronal Counts}

Development is one of Tinbergen's questions, and the Piagetian framework offers a useful method for studying the development of sensorimotor cognition. The potential mechanisms - another Tinbergian question - enabling sensorimotor cognition are illuminated by recent advances in neurology. Instead of comparing taxa in traditional terms using relative and absolute brain sizes, the total number of neurons in their brain and separate brain areas can now be measured. This method has revealed that the human brain is not in principle extraordinary - just a scaled-up primate brain. Primates have relatively high packing densities of neurons, such that they have more neurons than other mammals of identical brain sizes, and humans simply have the largest brains of primates, totaling 86 billion neurons (Herculano-Houzel, 2012, 2017). Bird brains are differently structured and generally smaller than mammalian brains but have larger packing densities: parrot and passerine brains have twice as many neurons as primate brains of the same size (Olkowicz et al., 2016), which explains their excellent performance on various cognitive tasks (Herculano-Houzel, 2017; Lambert et al., 2019).

Not only the absolute neuronal count but also their distribution within the brain may clarify the mechanism behind information-processing capacities across taxa. Three brain subdivisions are typically studied: pallium, cerebellum and 'rest of brain' (Herculano-Houzel, 2017; Olkowicz et al., 2016). The pallium is part of the amniote telencephalon and is akin to the cerebral cortex in mammals. It contains associative functions, involves sensorimotor integration and executive functions, and is associated with enhanced domain-general cognition (Güntürkün, Stacho, \& Ströckens, 2017; Sayol, Lefebvre, \& Sol, 2016). The cerebellum is a conserved vertebrate brain structure that plays a major role in coordination, learning, anticipatory reactions and behavioral control. The 'rest of brain' variable refers to all other brain areas with various functions: subpallium, diencephalon and brainstem - but not olfactory bulbs, which are often missing from specimens (Herculano-Houzel, 2017; Olkowicz et al., 2016).

The neuronal density in the pallium of parrots and passerines exceeds those of primates, which results in fast information processing and advanced cognitive capacities despite their small brains (Olkowicz et al., 2016). Moreover, the pallium is disproportionally large and houses an increasingly large number of neurons in large-brained birds, such as parrots and corvids, compared to mammals (Güntürkün 
et al., 2017; Olkowicz et al., 2016; Sayol et al., 2016). Consequentially, disproportionately large bird brains contain relatively few neurons in the cerebellum and rest of brain. In contrast, the majority of neurons in the mammalian brain are found in the cerebellum. For instance, the pallium of passerines and parrots houses around $33-61 \%$ of all brain neurons, but the relatively large pallium of humans contains only $19 \%$ of all brain neurons and their cerebellum $80 \%$ (Herculano-Houzel, Catania, Manger, \& Kaas, 2015; Olkowicz et al., 2016). Thus, the large differences between (and often within) the neuronal scaling rules of bird and mammal brains make measures of relative and absolute brain size rather uninformative. Instead, absolute numbers of neurons in the brain and various subdivisions are now available for many taxa and will likely prove to be a stronger predictor of cognitive abilities (Herculano-Houzel, 2017).

This study investigates the development of sensorimotor cognition in common ravens (Corvus corax) and compares their development with that of twelve other species previously tested on similar tasks, without a strict adherence to Piagetian theory. Ravens are known for their cognitive complexity and flexibility, as is the corvid family to which they belong (Bugnyar, 2013; Emery \& Clayton, 2004; Güntürkün \& Bugnyar, 2016; Heinrich, 2011; van Horik, Clayton, \& Emery, 2012). Corvid brains are scaled-up passerine brains, and thus have large absolute numbers of neurons that enable their cognitive prowess (Olkowicz et al., 2016). Sensorimotor cognition has never been explicitly studied in adult ravens, though it can be inferred from many studies (e.g., Auersperg et al., 2015; Bugnyar, Stöwe \& Heinrich, 2007; Heinrich, 1995a; Jacobs et al., 2014). Their developmental patterns have been studied extensively in other areas, such as play (Bugnyar, Schwab, Schloegl, Kotrschal, \& Heinrich, 2007; Osvath, Osvath, \& Bååth, 2014), neophobia (Heinrich, 1995b; Miller, Bugnyar, Pölzl, \& Schwab, 2015; Stöwe et al., 2006), motor self-regulation (Kabadayi, Jacobs, \& Osvath, 2017), social relations (Loretto, Fraser, \& Bugynar, 2012; Miller, Laskowski, Schiestl, Bugnyar, \& Schwab, 2016; Osvath, Osvath, et al., 2014; Stöwe et al., 2008), and gaze following (Schloegl, Kotrschal, \& Bugnyar, 2007). The development of object permanence - memory of an object's location despite it not being currently perceivable - is also framed in Piagetian stages, and has frequently been studied in a wide variety of taxa (Auersperg, Szabo, von Bayern, \& Bugnyar, 2014; Doré \& Dumas, 1987; Gómez, 2004; Lambert et al., 2019; Parker \& McKinney, 1999; Pepperberg, Willner, \& Gravitz, 1997), including six corvid species with various caching propensities (Hoffmann, Rüttler, \& Nieder, 2011; Pollok, Prior, \& Güntürkün, 2000; Salwiczek, Emery, Schlinger, \& Clayton, 2009; Ujfalussy, Miklósi, \& Bugnyar, 2013; Zucca, Milos, \& Vallortigara, 2007). Ravens show comparably quick development and reach the highest stages of object permanence (Bugnyar, Stöwe, et al., 2007). The current study investigates whether this is also the case for sensorimotor cognition and compares its development across thirteen species. The cognitive development of these species is then analyzed and compared in the light of their brain sizes and neuronal counts.

\section{Method}

\section{Subjects}

We tested five raven chicks, of which four were female. All were ringed for individual identification. We hand-raised four chicks at the Lund University Corvid Cognition Station after removing them from four nests in the wild. At the time of collection, two females were five weeks old, one female was four weeks old, and the male was two weeks old. They were initially kept together in an artificial nest. After they fledged in their seventh week they were kept in a large aviary with a group of five adults. The fifth chick (female) was hatched in captivity at a zoo (Skånes Djurpark, Sweden), where it was removed from the nest at three weeks old and hand-raised thereafter.

Time of fledging was used to estimate their ages. Ravens fledge around 44 days after hatching with a few days of variation (based on five different nests from the previous four years as well as the fledging date of the hand-raised ravens at the station). This estimation was accompanied and independently corroborated by the before-fledging age estimations of the caretakers who had years of experience in hand-raising ravens and had photographic collections of ravens of different ages. The study ended when the ravens were eleven weeks old. During the same period, they took part in a study on the 
development of motor self-regulation, which involved different tasks and materials (Kabadayi et al., 2017).

\section{Design and Procedure}

Before starting the study, we adapted the Piagetian sensorimotor series for testing ravens by selecting tasks from previous Piagetian studies done with twelve species (see Introduction) after assessing their feasibility. The stage categorization of each behavior was taken from these previous studies to maintain comparability. All selected behaviors occur in adult ravens, and several of them had previously been observed in young yellow-crowned parakeets - the only bird species tested on this developmental series (Funk, 2002). The resulting 37 behaviors were spontaneous actions or tasks induced by the experimenter if necessary (e.g., placing a toy out of reach with a string attached for the subject to pull). The tasks are described in Table 1.

We looked for all tasks in every session because they may occur under various circumstances with variable frequencies, which would be missed by focusing on a limited number of tasks per session. Activity patterns of young ravens vary strongly within a day and over development, so instead of scheduled sessions, observations were spread over the day and week, stopping when subjects were resting and continuing when they woke up. Testing took place two to four times per week in the subject's home enclosure in the presence of two or three experimenters, to whom all subjects were habituated and showed no signs of distress. The methods for the zoo-housed subject differed in that typically only one experimenter was present (who was also always one of the experimenters with the other birds), but these sessions were videotaped (See supplemental video).

Before each test session, a set of objects (see Figure 1) was placed in and around the nest, or in the enclosure once the chicks were fledged. The chicks never showed a neophobic response to them - as expected at that age (Heinrich, 1995b; Miller et al., 2015). In addition, they often interacted with various objects in their aviary, such as sticks, stones, bones, hay, soil, plants, perches and a plastic bath. The observed behaviors were hence not restricted to the pictured objects. Food rewards were never present, as the birds could not yet eat on their own at the onset of the study. Instead, various objects from the object set (see Figure 1) were used when tasks involved obtaining a reward, and they proved to be sufficiently motivating (for object preferences in adult ravens, see Auersperg et al., 2015; Heinrich, 1995b; Jacobs et al., 2014). A subject was considered to pass if it demonstrated the behavior at least twice in the same week and two experimenters agreed on its occurrence. Only descriptive statistics of their development are reported because further analyses are not very informative in Piagetian sensorimotor theory, in which order and structure of development are more important than its exact timings and frequencies, as discussed above.

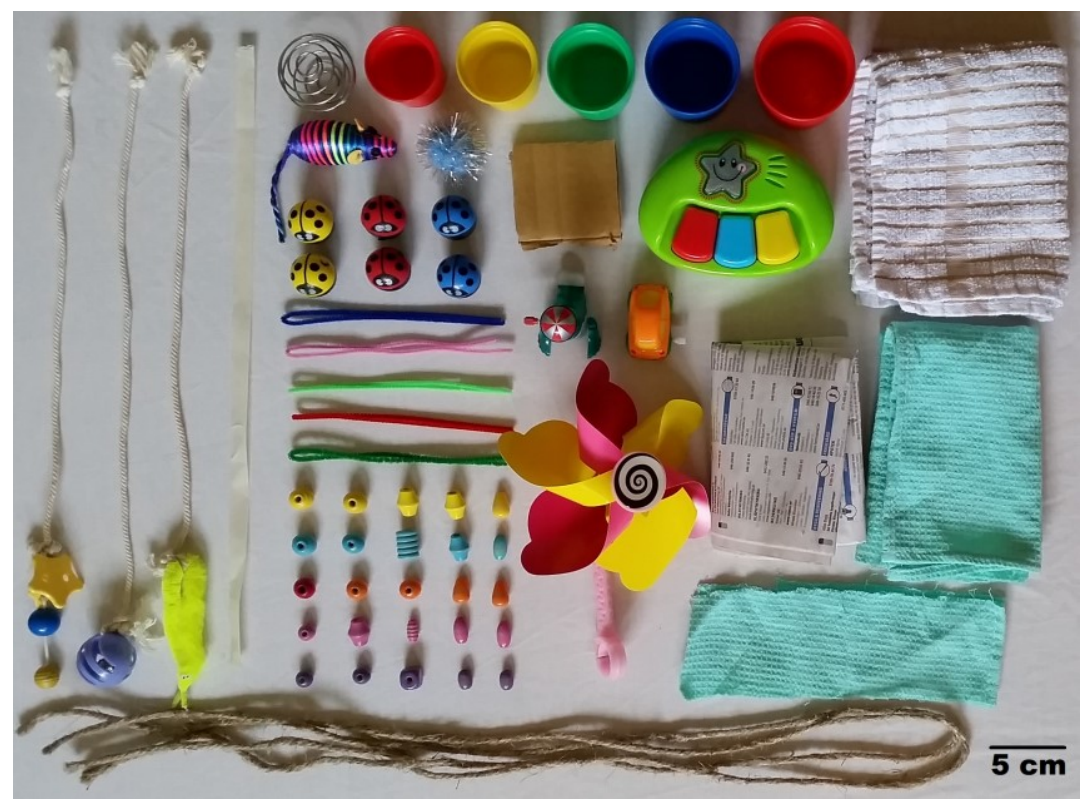

Figure 1. The materials used in this study in addition to those already present in the aviaries (e.g. sticks, stones, bones, hay, soil, plants, perches, and a plastic bath). 
Table 1

The 37 Tasks Used in This Study

\begin{tabular}{|c|c|c|}
\hline Stage & Task & Description \\
\hline 2 & 1 & Self-preening \\
\hline $\begin{array}{l}\text { Primary circular } \\
\text { reactions }\end{array}$ & 2 & Self-scratching \\
\hline \multirow{6}{*}{$\begin{array}{l}3 \\
\text { Secondary circular } \\
\text { reactions }\end{array}$} & 3 & Orients and attends to moving object \\
\hline & 4 & Repeatedly plays with objects \\
\hline & 5 & Orients and attends to sound produced by an object \\
\hline & 6 & $\begin{array}{l}\text { Displays motor activity when wind-up toy stops moving after being activated by } \\
\text { experimenter }\end{array}$ \\
\hline & 7 & Allo-preening \\
\hline & 8 & Shakes or otherwise interacts with an object to reproduce sound \\
\hline \multirow{16}{*}{$\begin{array}{c}4 \\
\text { Coordination of } \\
\text { secondary schemes }\end{array}$} & 9 & Locomotion as a means to retrieve an object \\
\hline & 10 & $\begin{array}{l}\text { Puts two objects in global relation to each other (e.g. placing one underneath the } \\
\text { other) }\end{array}$ \\
\hline & 11 & Carries or drags object \\
\hline & 12 & Turns over or rotates object \\
\hline & 13 & Acts on mobile parts of a wind-up toy after being activated by experimenter \\
\hline & 14 & Holds object with beak and foot simultaneously \\
\hline & 15 & Lets go of an object to reach for another \\
\hline & 16 & $\begin{array}{l}\text { Pulls a string horizontally to retrieve object (the proximal end of a string [ } 30 \mathrm{~cm} \text { long] } \\
\text { protrudes through a mesh barrier that prevents direct access to goal object attached to } \\
\text { string) }\end{array}$ \\
\hline & 17 & Tears object apart \\
\hline & 18 & Collects several objects \\
\hline & 19 & Puts body part in a container or hole in object \\
\hline & 20 & Digs a hole \\
\hline & 21 & $\begin{array}{l}\text { Pulls cloth to retrieve object it supports (the proximal end of a cloth }[6 \times 22 \mathrm{~cm}] \\
\text { protrudes through a mesh barrier that prevents direct access to goal object lying on top } \\
\text { of cloth) }\end{array}$ \\
\hline & 22 & $\begin{array}{l}\text { Avoids choosing unrewarded supporting cloth (as in } 21 \text {, but with an unbaited cloth } \\
\text { present next to baited one) }\end{array}$ \\
\hline & 23 & Puts objects in water \\
\hline & 24 & $\begin{array}{l}\text { Pulls a string vertically to retrieve object (the baited } 30-\mathrm{cm} \text {-long string is suspended } \\
\text { below a perch) }\end{array}$ \\
\hline \multirow{10}{*}{$\begin{array}{l}5 \\
\text { Tertiary circular } \\
\text { reactions }\end{array}$} & 25 & Acts directly on part causing movement of wind-up toy \\
\hline & 26 & Repeatedly drops object and watches it fall \\
\hline & 27 & Tosses object in air \\
\hline & 28 & Puts two objects in specific relation to each other (e.g. stacking, inserting) \\
\hline & 29 & Bounces ball \\
\hline & 30 & Puts object in container repeatedly \\
\hline & 31 & Spins wheel \\
\hline & 32 & Balances object on another \\
\hline & 33 & Spins ball \\
\hline & 34 & Flails object back and forth in water \\
\hline \multirow{3}{*}{$\begin{array}{c}0 \\
\text { Mental } \\
\text { representation }\end{array}$} & 35 & Bunches cloth or rope into a ball \\
\hline & 36 & Puts object in cloth and wraps it up \\
\hline & 37 & Hangs cloth or string over perch, or places it along length of perch \\
\hline
\end{tabular}

Note. Stage 1 (reflexes) is not included because it is already present at hatching. 


\section{Analyses}

We analyzed the relationship between maximum stage achieved of these thirteen species (i.e., those tested on Piagetian sensorimotor development) and their adult absolute brain mass, relative brain mass, and number of neurons in the whole brain, pallium, cerebellum, and rest of brain. The data were collected from the literature or calculated along known taxon-specific scaling rules when direct measurements were unavailable (see Table 2). Statistical species comparisons of brain sizes and neuronal counts were performed using IBM-SPSS (v. 21). Non-parametric tests were performed because all six brain variables differed significantly from a normal distribution (Kolmogorov-Smirnov test; $D(13)>0.24$, $p<0.05)$. Piagetian development can be viewed as both continuous and categorical and was therefore separately analyzed as both.

Table 2

\begin{tabular}{|c|c|c|c|c|c|c|}
\hline Species & $\mathbf{M}_{\mathrm{BR}}$ & $\mathbf{M}_{\text {REL }}$ & $\mathbf{N}_{\text {BR }}$ & $\mathbf{N}_{\mathbf{C X}}$ & $\mathbf{N}_{\mathbf{C B}}$ & $\mathbf{N}_{\mathrm{RoB}}$ \\
\hline Common raven $^{\mathrm{a}}$ & 14.1 & 1.32 & 2171 & 1204 & 754 & 213 \\
\hline Yellow-crowned parakeet ${ }^{b}$ & 1.91 & 4.15 & 411 & 247 & 141 & 62 \\
\hline Grey wolf ${ }^{\mathrm{c}}$ & 86.5 & 0.44 & 2253 & 528 & 1677 & 48 \\
\hline Domestic cat $^{\mathrm{d}}$ & 34.9 & 0.78 & 1215 & 250 & 943 & 22 \\
\hline Tufted capuchin $^{\mathrm{e}}$ & 52.2 & 1.56 & 3691 & 1140 & 2490 & 61 \\
\hline Northern plains gray langur ${ }^{\mathrm{f}}$ & 113.8 & 1.00 & 7785 & 2268 & 5853 & 129 \\
\hline Stumptail macaque ${ }^{\mathrm{f}}$ & 101.1 & 1.28 & 7027 & 2031 & 5240 & 120 \\
\hline Long-tailed macaque ${ }^{g}$ & 46.2 & 0.81 & 3439 & 801 & 2573 & 65 \\
\hline Japanese macaque $^{f}$ & 98.6 & 1.04 & 6877 & 1984 & 5118 & 118 \\
\hline Bornean orangutan ${ }^{\mathrm{h}}$ & 511.8 & 0.93 & 32600 & 8900 & 26300 & 300 \\
\hline Western gorilla $^{\mathrm{h}}$ & 486.1 & 0.40 & 33400 & 9100 & 26400 & 300 \\
\hline Chimpanzee $^{f}$ & 376.1 & 0.78 & 21895 & 6919 & 17920 & 265 \\
\hline Human $^{\mathrm{i}}$ & 1509 & 2.16 & 86060 & 16340 & 69030 & 690 \\
\hline
\end{tabular}

$\mathrm{M}_{\mathrm{BR}}$, absolute brain mass ( $\mathrm{g}$ ); $\mathrm{M}_{\mathrm{REL}}$, relative brain mass (\% of body mass); $\mathrm{N}_{\mathrm{BR}}$, number of neurons in the whole brain (millions);

$\mathrm{N}_{\mathrm{CX}}$, number of neurons in the pallium (millions); $\mathrm{N}_{\mathrm{CB}}$, number of neurons in the cerebellum (millions); $\mathrm{N}_{\mathrm{RoB}}$, number of neurons in the rest of the brain (millions).

${ }^{a}$ Measured (Olkowicz et al., 2016).

${ }^{\mathrm{b}}$ Estimated based on body weight (Dunning, 2008) and parrot-specific scaling rules (Olkowicz et al., 2016).

${ }^{\mathrm{c}}$ Measured data on domestic dogs because wolf data are unavailable (Jardim-Messeder et al., 2017).

${ }^{\mathrm{d}}$ Measured (Jardim-Messeder et al., 2017).

${ }^{\mathrm{e}}$ Measured (Herculano-Houzel, Collins, Wong, \& Kaas, 2007; Herculano-Houzel et al., 2015).

${ }^{\mathrm{f}}$ Estimated based on $\mathrm{M}_{\mathrm{BR}}$ (DeCasien, Williams, \& Higham, 2017) and primate-specific scaling rules (Herculano-Houzel et al., 2007, 2015).

${ }^{g}$ Measured (Gabi, Collins, Wong, Kaas, \& Herculano-Houzel, 2010; Herculano-Houzel et al., 2015).

${ }^{\mathrm{h}} \mathrm{MBR}_{\mathrm{BR}}$ and $\mathrm{N}_{\mathrm{CB}}$ measured (Herculano-Houzel \& Kaas, 2011), and other variables estimated based on primate-specific scaling rules (Herculano-Houzel et al., 2007; Herculano-Houzel \& Kaas, 2011).

${ }^{\mathrm{i}}$ Measured (Azevedo et al., 2009; Herculano-Houzel et al., 2015).

\section{Results}

\section{Sensorimotor Development in Ravens}

The five ravens performed all 37 tasks, reached the final stage by their eleventh week, and developed in the typical incremental sequence. All stage-specific behaviors were acquired at the following mean ages ( \pm SD): stage 2 at 4.7 weeks $( \pm 0.76)$; stage 3 at 5.0 weeks $( \pm 0.49)$; stage 4 at 6.8 weeks $( \pm 0.33)$; stage 5 at 7.3 weeks $( \pm 0.63)$; and stage 6 at 8.5 weeks $( \pm 1.11)$. Stage 1 (reflexes) is not included because it is already present at hatching when these subjects were not yet obtained, but previous observations of parent-reared hatchlings unsurprisingly showed vital reflexive behaviors from their first days, such as gaping, feeding, and bringing the body in upright position. Figure 2 shows the age of acquisition of each task per subject. 


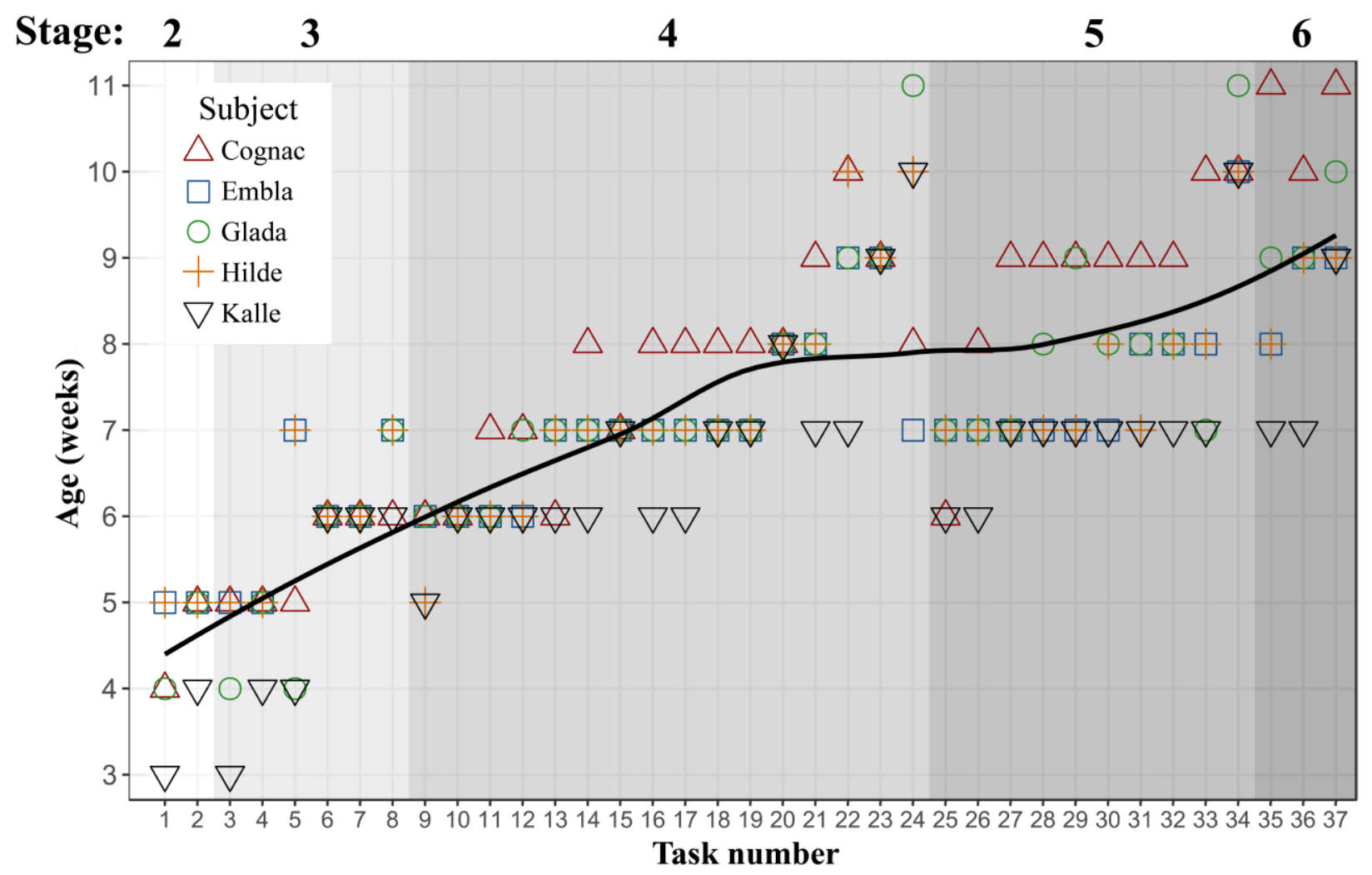

Figure 2. The age of acquisition of each task per subject. Task numbers refer to Table 1. Age is shown as week number, such that week $3=15-21$ days, etc. The loess curve across subjects is shown as a black line. Embla (female, collected at five weeks old), Glada (female, collected at five weeks old), Hilde (female, collected at four weeks old) and Kalle (male, collected at two weeks old) were raised together at the research station. Cognac (female, collected at three weeks old) was raised separately in a zoo (video examples of her performing several tasks are available in the supplementary materials).

The timing of stage 2 likely comes earlier: most subjects already performed these behaviors when we obtained them, while the youngest reached this stage at 4.0 weeks of age, almost a week earlier than the average for all five subjects. Self-scratching developed relatively late, which has a large impact on the mean age of onset because there were only two recorded behaviors for this stage. Self-preening developed around 3.7 weeks, considerably earlier than the average for all behaviors grouped into stage 2 (4.7 weeks), making the delay to stage 3 (mean 5.0 weeks) more substantial. Progression results in other stages are more reliable because they involved more tasks and subjects did not already perform these behaviors when we first obtained them.

The ravens' developmental sequence is comparable to that of other species, but their developmental rate is greatly accelerated. Figures 3 and 4 offer qualitative comparisons in sensorimotor development with the twelve other species tested previously. These figures differ from the means reported above because they show the range for each stage, which are often the only reported values in previous studies, and therefore the only means of comparison. 


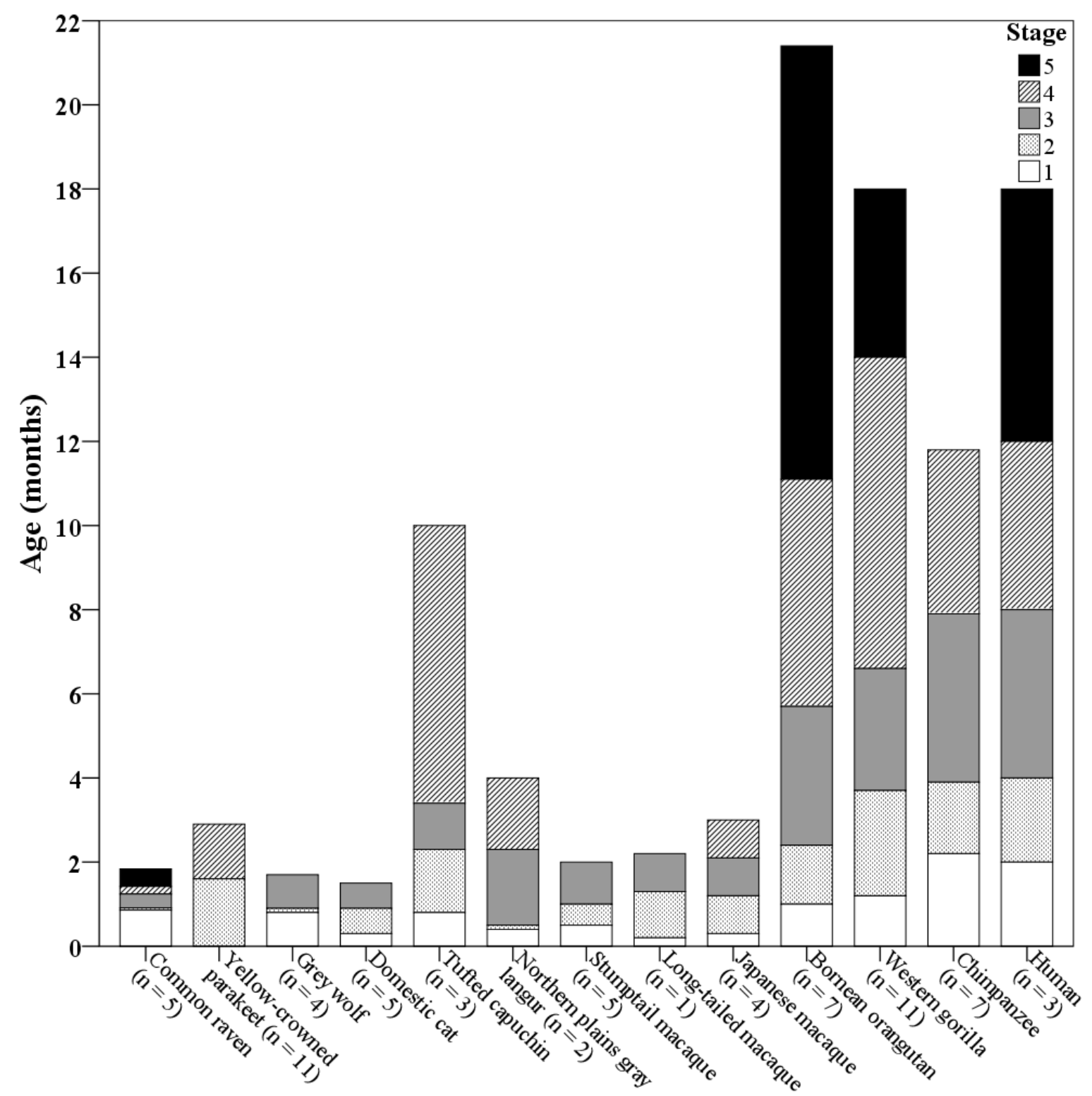

Figure 3. The development of Piagetian sensorimotor stages in thirteen species. The ages show weighted averages of stage onset across all studies done per species. The highest stage described for each species starts at the end of the top bar and does not have its own bar because its end is unknown. For example, humans transition to stage 6 at 18 months and chimpanzees transition to stage 5 around 12 months. The ages in humans are those originally described by Piaget as a reference point, although many authors claim they should be lower (e.g., Redshaw, 1978; Užgiris \& Hunt, 1975). The onset of stage 2 in ravens is likely earlier (see Results). The stages in yellow-crowned parakeets show some overlap, in which case the highest stage is shown. Only studies that explicitly tested Piagetian sensorimotor development are included. Thus, studies are excluded if they reported the stage of only adult animals (e.g., it is known that chimpanzees reach stage 6 but it is unclear when they do so: Chevalier-Skolnikoff, 1977, 1989; Mathieu, Daudelin, Dagenais, \& Décarie 1980), or behaviors that can be assigned secondarily to a certain stage (e.g., some corvids and parrots likely reach at least stage 5 based on their tool use: Auersperg, Szabo, von Bayern, \& Kacelnik, 2012; Kenward et al., 2011; Lambert, Seed, \& Slocombe, 2015; Rutz et al., 2016). Common raven (Corvus corax): this study. Yellowcrowned parakeet (Cyanoramphus auriceps): Funk, 2002. Grey wolf (Canis lupus lupus): Fiset et al., 2014. Domestic cat (Felis silvestris catus): Dumas \& Doré, 1991. Tufted capuchin (Sapajus apella): Spinozzi, 1989. Northern plains gray langur (Semnopithecus entellus): Chevalier-Skolnikoff, 1982. Stumptail macaque (Macaca arctoides): Chevalier-Skolnikoff, 1976, 1977; Parker, 1977. Long-tailed macaque (M. fascicularis): Potí, 1989. Japanese macaque (M. fuscata): Antinucci et al., 1982; Potí, 1989. Bornean orangutan (Pongo pygmaeus): Chevalier-Skolnikoff, 1982, 1983. Western gorilla (Gorilla gorilla): Chevalier-Skolnikoff, 1976, 1977, 1982; Redshaw, 1978; Spinozzi \& Natale, 1989. Chimpanzee (Pan troglodytes): ChevalierSkolnikoff, 1982; Hallock \& Worobey, 1984; Potí \& Spinozzi, 1994. Human (Homo sapiens sapiens): Piaget, 1952. 


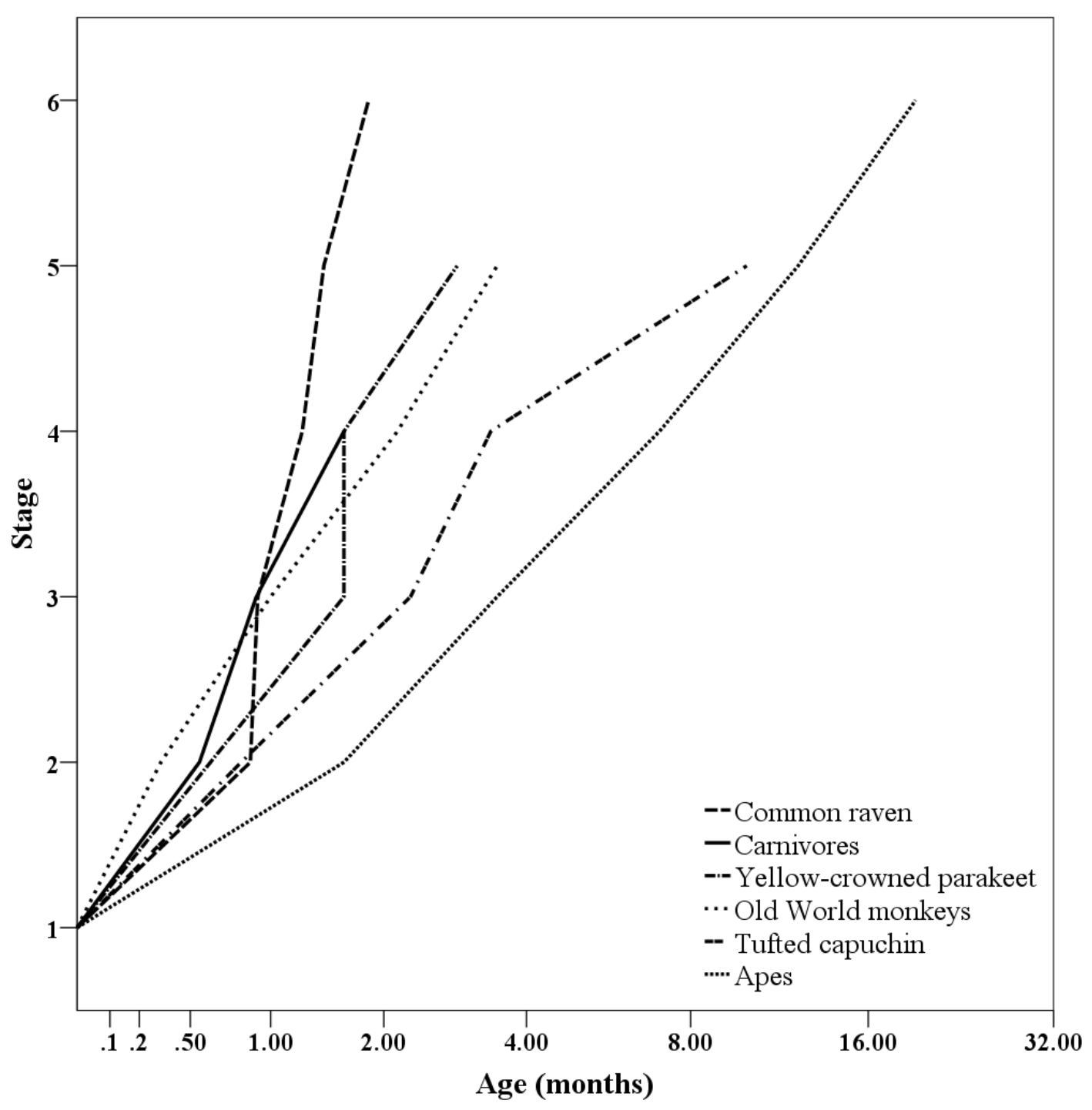

Figure 4. Stage progression as a function of age of stage onset. Closely related species have been grouped together for clarity and because their development was highly similar; specifically, final stage reached and the ages of acquisition are similar for closely related species (see Figure 3). Higher phylogenetic levels show more variation. Heterochrony can be seen in several ways. The onset of sensorimotor cognition is the same for all thirteen species because they start life in stage 1. No species skips a stage or goes through a different stage order, so the sequence is also identical for all species. As expected, the rate of sensorimotor development is slower in species with a slower life history. Its offset is not clearly predicted by phylogeny or developmental rate since the only taxa known to reach the final stage (great apes and ravens) differ strongly in these respects, and the timings and final stage achieved are not necessarily similar in closely-related taxa.

\section{Comparative Neuronal Counts}

Next, we analyzed the relationship between maximum stage achieved of these thirteen species and their brain size and neuronal counts (see Table 2). With Piagetian development considered as a continuous variable, maximum stage achieved was positively and significantly correlated to number of neurons in the pallium $(r \mathrm{~s}=.66, p=.02)$ and rest of brain $(r \mathrm{~s}=.79, p=.001)$. In contrast, there were no significant correlations between maximum stage achieved and absolute brain mass $(r \mathrm{~s}=.45, p=.13)$, relative brain mass $(r \mathrm{~s}=.25, p=.41)$, number of neurons in the whole brain $(r \mathrm{~s}=.52, p=.07)$ or number of neurons in the cerebellum $(r \mathrm{~s}=.45, p=.13)$. Figure 5 shows the relationship between maximum stage achieved and number of pallial neurons. 


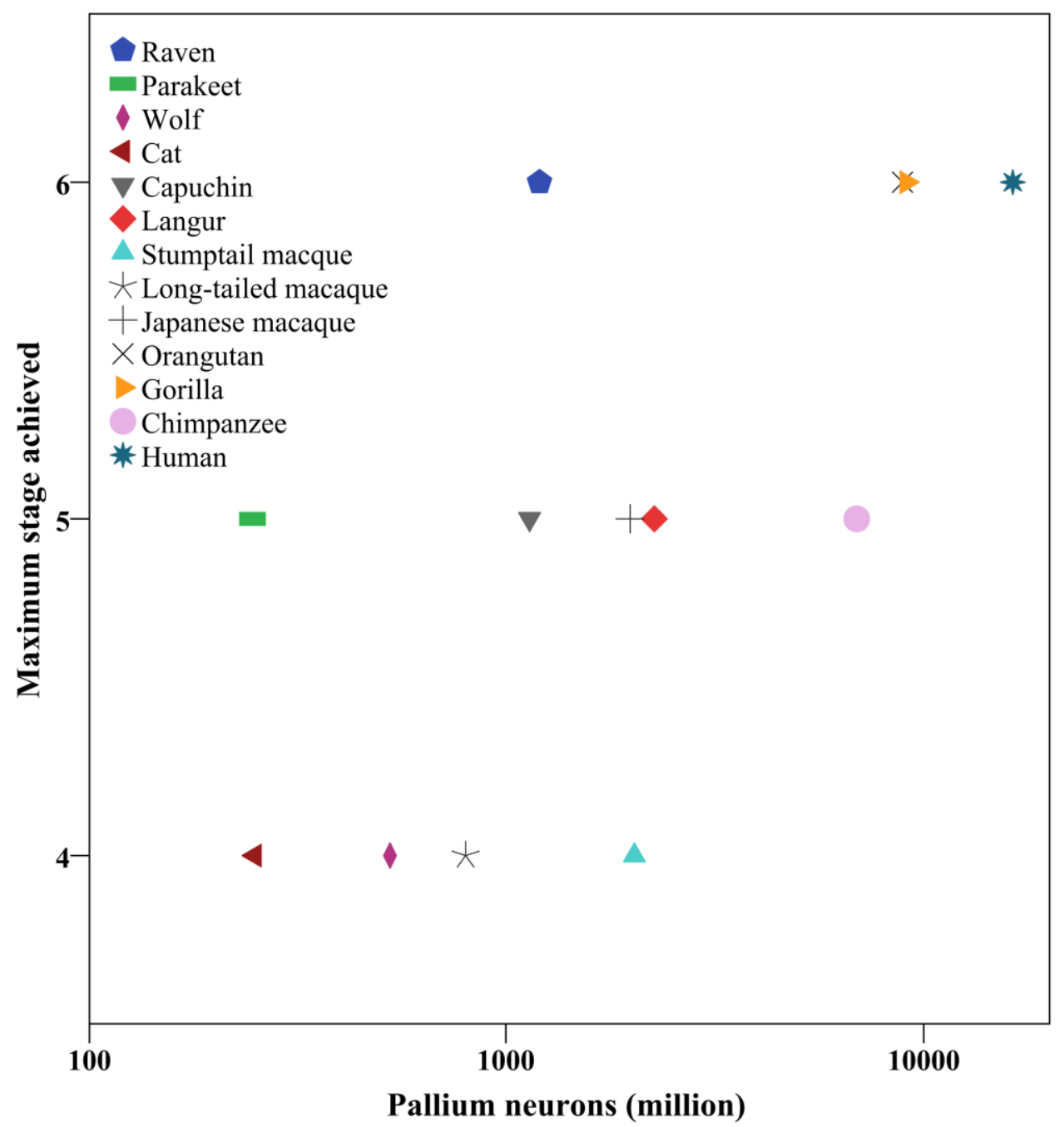

Figure 5. The relationship between number of neurons in the pallium and maximum Piagetian stage achieved for the thirteen species (data from Table 2).

Similar results were obtained when considering maximum stage achieved as a categorical, ordinal variable. Exact two-tailed Jonckheere tests revealed that the maximum stage achieved was significantly higher for species with larger numbers of neurons in the pallium $(J=46, p=.02)$ and rest of brain $(\mathrm{J}=50$, $p=.003)$. No statistically significant relationships were found between maximum stage achieved and absolute brain mass $(J=41, p=.10)$, relative brain mass $(J=35, \mathrm{p}=.43)$, number of neurons in the whole brain $(J=43, p=.06)$ or number of neurons in the cerebellum $(J=41, p=.10)$, although some approached traditional levels of statistical significance, which is unsurprising given the close association between these variables. Thus, regardless of whether maximum stage achieved is considered, continuous or categorical, species with more neurons in their pallium and rest of brain (as adults) reach a higher sensorimotor stage, though the sample size is limited. 


\section{Discussion}

\section{Sensorimotor Cognition and Development}

Ravens reach the final sensorimotor stage through the same sequence as great apes, including humans, albeit at a markedly accelerated rate. Together with Funk's (2002) study on yellow-crowned parakeets, this shows that the Piagetian sensorimotor series can be applied successfully to birds and offers a useful tool for investigating comparative cognitive development. The results demonstrate that the development of sensorimotor cognition in ravens and many primates is similar, despite approximately 324 million years (dos Reis et al., 2015) of independent evolution along with significant anatomical and ecological differences (Güntürkün \& Bugnyar, 2016; Lambert et al., 2019; Osvath et al., 2014a).

However, there can still be substantial differences among species reaching the same stage. For example, some researchers concluded that macaques do not perform certain behaviors typical of stage 3, such as repetitive object play (Parker, 1977; Parker \& McKinney, 1999). This is in stark contrast to ravens, which played extensively and repetitively with objects, starting at 4.3 weeks until the end of the study (11 weeks). Previous studies have shown that ravens in their sixth and seventh weeks spend more than a third of their waking time playing with objects (Osvath, Osvath, et al, 2014), and that this propensity increases over the subsequent weeks (Bugnyar, Stöwe, et al., 2007; Kenward et al., 2011), peaking at the juvenile stage (3-8 months), and dropping thereafter (Miller et al., 2015). Ravens manipulate objects more frequently than New Caledonian crows (Corvus moneduloides), jackdaws $(C$. monedula), and carrion crows (C. corone) (Auersperg et al., 2015; Jacobs et al., 2014, Miller et al., 2015). Such strong inclinations to explore and play can be beneficial. For example, ravens learn about the pilfering propensities of others by play caching (Bugnyar, Schwab, et al., 2007), and ravens that are more explorative towards objects are more likely to innovate (Miller, Schwab, \& Bugnyar, 2016). When our ravens had just learned to walk and fly at the end of their second month, they could already perform means-end tasks that some mammals and birds cannot do as adults: pulling a string horizontally or vertically to obtain an attached reward (Jacobs \& Osvath, 2015).

One of the most prominent criticisms of Piagetian theory has been that its tests are unsuitable for investigating the cognitive abilities they are purported to show, mainly because performance on these tasks (1) requires deliberate action that may be unreliable despite accurate representation; (2) is determined by a mixture of cognitive abilities; and (3) is confounded by other (non-controlled) factors (Chevalier-Skolnikoff, 1989; Doré \& Dumas, 1987; Fragaszy, 1989; Gelman \& Baillargeon, 1983; Lourenço, 2016; Lourenço \& Machado, 1996; Pepperberg, 2002; Vauclair, 2012). This has led to methodological changes, such as using attention as a measure for expectancy violation (Winters, Dubuc, \& Higham, 2015), which has been tested in corvids in the domains of support relations, object causality, understanding of third-party relations, and cross-modal individual recognition (Bird \& Emery, 2010; Davidson, Miller, Loissel, Cheke, \& Clayton, 2017; Kondo, Izawa, \& Watanabe, 2012; Massen, Pašukonis, Schmidt, \& Bugnyar, 2014).

Although this may be a fair criticism of other parts of the theory, the sensorimotor series continues to be a useful tool for describing operationalized and observable behavioral changes rather than isolated cognitive abilities independent of action. Piagetian sensorimotor theory classifies novel actions along a gradient of increasing complexity, coordination, intentionality, functionality, voluntary control, affordance learning, and motor-action variability, leading to an overall increase in the behavioral repertoire (Doré \& Dumas, 1987; Lourenço, 2016; Parker \& McKinney, 1999). Many sensorimotor abilities are ecologically relevant, retained throughout life, foundational for more complex behaviors found in adults, and amenable to interspecies comparisons important to studying cognitive evolution. The sensorimotor series therefore offers a valuable addition to the more frequently tested object permanence series, which is also based on Piagetian theory and passed by ravens in every developmental stage and in close association with their caching abilities (Bugnyar, Stöwe, et al., 2007).

Evolution involves developmental change, which restricts the available substrates that selection can act on because function must be preserved (Gould, 1977; Holekamp, Swanson, \& Van Meter, 2013; 
Parker \& Gibson, 1979; West-Eberhard, 2003). Early development thereby becomes relatively conserved in phylogeny. Traits that develop later are more likely to be altered by evolution, because fewer other traits depend on them, allowing them more degrees of freedom. Terminal changes in development are often determined by timing: so-called called heterochrony, characterized by changes in onset, rate, or offset of a trait, which becomes extended (overdevelopment) or truncated (underdevelopment). Humans are typically described as progressively overdeveloped in their life history, brain growth, and cognition, arising mainly through delayed developmental offset (Langer, 2006; Parker \& McKinney, 1999; Rosati et al., 2014; Wobber et al., 2014; but see Herculano-Houzel, 2018).

Heterochrony, which can affect single traits independently, depends on out-group comparisons, so it is often inappropriate to call a species completely under- or overdeveloped. For example, expansion of the telencephalon starts and ends relatively late in parrots and passerines, especially corvids, compared to other birds (Charvet \& Striedter, 2011). In general, birds develop more quickly and have higher neuronal density than mammals. Ravens have around 64 million pallial neurons more than capuchin monkeys, even though their pallium is nearly four times lighter (Olkowicz et al., 2016). The structure of bird brains is complex, even as bird skulls stop growing at an early stage - resulting in proportionately large eyes and brains. The skulls of adult birds resemble those of alligator embryos, yet their beaks are elongated through overdevelopment (Bhullar et al., 2012), thus exemplifying the non-uniform interplay between development and evolution.

Piagetian sensorimotor tests are useful for comparing species' development in terms of heterochrony, but the dataset so far is limited. Only thirteen species have been tested (see Figures 3 and 4), often in single studies with low sample sizes, species-inappropriate methods, or untimely discontinuations. Not enough clades are represented to conduct reliable phylogenetic analysis. The sensorimotor period is only the first of four in Piagetian theory; when an agent reaches its end, cognitive development continues, but this further development has been studied even less. Cognitive differences between species become more apparent in later periods (see Figure 3; Doré \& Dumas, 1987; Gómez, 2004; Parker \& McKinney, 1999; Wobber et al., 2014). Despite the limitations of the available data, we hope to illustrate the potential of comparative developmental methods for the study of cognitive evolution (see also MacLean et al., 2012; Parker \& McKinney, 1999; Rosati et al., 2014).

The first pattern that becomes clear from comparing the sensorimotor development of these thirteen species (see Figures 3 and 4) is that stage one is present from birth or hatching: i.e., there is no difference in sensorimotor development onset. Although all species are born with appropriate selfpreservation behaviors, some might begin life at a "later" stage. Altricial birds such as ravens are relatively immobile and strongly rely on their parents at hatching, and they do not show stage 2 behaviors (repeated actions towards the own body) until a later age. In contrast, precocial birds hatch with feathers, open eyes, and active locomotion. It is therefore possible that they reach higher stages soon after hatching. For example, young domestic chickens (Gallus gallus domesticus) tested shortly after hatching show advanced cognitive abilities in domains such as geometry, objects, space, agency, and numbers (Vallortigara, 2012a, 2012b). It is therefore likely that studies on their sensorimotor development from a Piagetian perspective would demonstrate large differences in heterochrony compared to altricial birds and mammals.

The thirteen species tested thus far are altricial and follow the same developmental sequence, which increases stepwise in the predicted order. However, the rate and offset vary substantially, with great apes developing considerably more slowly than other taxa. The developmental patterns suggest that timing and final stage achieved are conserved among more closely related species (see Figure 3), such that carnivores, Old World monkeys, and apes can each be grouped together (see Figure 4). The rate of sensorimotor development in capuchins is closer to that of apes than other monkeys (see also Fragaszy, 1990; Fragaszy, Baer, \& Adams-Curtis, 1991). They reach stage five and possibly stage six (ChevalierSkolnikoff, 1989), whereas some macaque species do not. Ravens reach stage six despite the large phylogenetic distance to apes. Carnivores do not reach the cognitive level of most primates, probably because their locomotion mode restricts their interactions with the environment, whereas the requirement for strong bite force constraints skull shape, which limits brain size evolution (Holekamp et al., 2013). 
Time to walking onset post-conception is largely determined in mammals by brain size and mode of locomotion, which explains why carnivores develop faster than most primates (Garwicz, Christensson, \& Psouni, 2009). The number of pallial neurons in their brain is also limited by body size due to metabolic constraints (Jardim-Messeder et al., 2017).

\section{Comparative Neuronal Counts}

Of these thirteen species, those that have higher absolute numbers of neurons in the pallium and rest of brain reach a higher final stage (see Figure 5). (Note that neuronal counts were estimated, not measured, for several species; see Table 2.) In contrast, absolute and relative brain size proved to be poor predictors. The neuronal number of bird and mammal brains scale very differently, often within each clade too, so comparisons become more informative when building on neuronal numbers rather than the traditional absolute and relative brain size (Herculano-Houzel, 2017; Olkowicz et al., 2016). For instance, human brains are over a hundred times heavier than raven brains, yet their number of neurons is forty times as large in the whole brain, fourteen times as large in the pallium and three times as large in the rest of the brain (see Table 2). Compared to ravens, humans have 92 times more neurons in the cerebellum, even though their relative cerebellar sizes are similar $(10 \%$ of the whole brain in humans and $8 \%$ in ravens [Herculano-Houzel et al., 2015; Olkowicz et al., 2016]).

The pallium plays an important role in sensorimotor integration and executive functions, so the association between number of pallial neurons and maximum Piagetian stage achieved - a measure of their sensorimotor cognition - was expected. Surprisingly, the same association was found with number of neurons in the rest of the brain, which is a combination of several brain subdivisions with various functions. Moreover, number of neurons in the cerebellum or whole brain had no such significant associations. The cerebellum is typically considered to be crucial for coordination and behavioral control and would therefore be expected to contain more neurons in species reaching higher stages. These analyses build on a relatively small sample size so future testing of more species may yield different - and more accurate - results. Nonetheless, relating performance to neuronal counts is a promising avenue for illuminating potential mechanisms of cognitive abilities across taxa (Herculano-Houzel, 2017; Olkowicz et al., 2016).

Hypotheses on the evolution of cognition can be tested by investigating sensorimotor development across species, even when distantly related. Complex cognitive abilities appear to have evolved independently in several bird and mammal clades. Although many researchers have argued that this shows convergent evolution (independent evolution of similar traits based on different underlying developmental structures) (e.g., Emery \& Clayton, 2004; van Horik et al., 2012), our present findings do not support this hypothesis, given that sensorimotor cognition is built on shared developmental pathways across species. This implies at least partial parallelism (independent evolution of similar traits based on the same underlying developmental structures) and the likelihood that advanced cognitive abilities develop in similar fashion across species (Güntürkün \& Bugnyar, 2016; Osvath, Kabadayi, et al., 2014). Another example is motor self-regulation, which develops at different paces but in a parallel pattern in ravens, rhesus macaques (Macaca mulatta) and human infants (Kabadayi et al., 2017). Claims of parallelism have been made previously when comparing the cognitive abilities of capuchins and apes (Melin et al., 2014; Padberg et al., 2007; Parker \& Gibson, 1977). The present finding of shared developmental patterns supports the possibility of partial parallel cognitive evolution between birds and mammals.

\section{Conclusion}

Development is an important but largely overlooked aspect of cognitive evolution - one that can greatly constrain the cognitive abilities of adults. Sensorimotor cognition forms the foundation for many complex cognitive skills, such as means-end understanding, inhibitory control and behavioral flexibility. In this study, we have described ravens' development on 37 tests of sensorimotor cognition. We 
discovered many parallels with other species, even distantly related ones, with variation occurring only in rate and offset - not onset or sequence - of sensorimotor development. We hope to have illustrated the significant potential of this approach by comparing thirteen species in terms of their cognitive development and neuronal numbers of various brain subdivisions, with the anticipation that many more species can be added in the future to allow for more robust comparisons, leading to a better understanding of the evolution of cognition. The study of animal cognition cannot become comprehensive without research on both ontogeny and phylogeny.

\section{Acknowledgments}

We thank the Crafoord Foundation and the Swedish Research Council (2012-1235 and 2014-6402) conjoined with Marie Sklodowska Curie Actions, Cofund (INCA 600398), for funding. We are grateful to Skånes Djurpark for allowing us to do research with their ravens. All applicable international, national and/or institutional guidelines for the care and use of animals were followed. All procedures performed were in accordance with the ethical standards set by the Swedish Board of Agriculture concerning noninvasive research with ravens. The four ravens kept at the Lund University Corvid Cognition Station were caught in the wild according to permission by the Swedish Environmental Protection Agency (NV 0417010). The facility has been approved by the Swedish Agricultural Board (5.2.18-5395/16).

\section{References}

Antinucci, F., Spinozzi, G., Visalberghi, E., \& Volterra, V. (1982). Cognitive development in a Japanese macaque (Macaca fuscata). Annali dell' Istituto Superiore di Santita, 18, 177-184.

Auersperg, A. M., Szabo, B., von Bayern, A. M., \& Bugnyar, T. (2014). Object permanence in the Goffin cockatoo (Cacatua goffini). Journal of Comparative Psychology, 128, 88-98.

Auersperg, A. M., Szabo, B., von Bayern, A. M., \& Kacelnik, A. (2012). Spontaneous innovation in tool manufacture and use in a Goffin's cockatoo. Current Biology, 22, R903-R904.

Auersperg, A. M., van Horik, J. O., Bugnyar, T., Kacelnik, A., Emery, N. J., \& von Bayern, A. M. (2015). Combinatory actions during object play in psittaciformes (Diopsittaca nobilis, Pionites melanocephala, Cacatua goffini) and corvids (Corvus corax, C. monedula, C. moneduloides). Journal of Comparative Psychology, 129, 62-71.

Azevedo, F. A., Carvalho, L. R., Grinberg, L. T., Farfel, J. M., Ferretti, R. E., Leite, R. E., ... Herculano-Houzel, S. (2009). Equal numbers of neuronal and nonneuronal cells make the human brain an isometrically scaled-up primate brain. Journal of Comparative Neurology, 513, 532-541.

Bateson, P., \& Laland, K. N. (2013). Tinbergen's four questions: An appreciation and an update. Trends in Ecology \& Evolution, 28, 712-718.

Bhullar, B.-A. S., Marugán-Lobón, J., Racimo, F., Bever, G. S., Rowe, T. B., Norell, M. A., \& Abzhanov, A. (2012). Birds have paedomorphic dinosaur skulls. Nature, 487, 223-226.

Bird, C. D., \& Emery, N. J. (2010). Rooks perceive support relations similar to six-month-old babies. Proceedings of the Royal Society B, 277, 147-151.

Bugnyar, T. (2013). Social cognition in ravens. Comparative Cognition \& Behavior Reviews, 8, 1-12.

Bugnyar, T., Schwab, C., Schloegl, C., Kotrschal, K., \& Heinrich, B. (2007). Ravens judge competitors through experience with play caching. Current Biology, 17, 1804-1808.

Bugnyar, T., Stöwe, M., \& Heinrich, B. (2007). The ontogeny of caching in ravens, Corvus corax. Animal Behaviour, 74, 757-767.

Carey, S., Zaitchik, D., \& Bascandziev, I. (2015). Theories of development: In dialog with Jean Piaget. Developmental Review, 38, 36-54.

Charvet, C. J., \& Striedter, G. F. (2011). Developmental modes and developmental mechanisms can channel brain evolution. Frontiers in Neuroanatomy, 5, 4.

Chevalier-Skolnikoff, S. (1976). The ontogeny of primate intelligence and its implications for communicative potential: A preliminary report. Annals of the New York Academy of Sciences, 280, 173-211.

Chevalier-Skolnikoff, S. (1977). A Piagetian model for describing and comparing socialization in monkey, ape, and human infants. In S. Chevalier-Skolnikoff \& F. E. Poirier (Eds.), Primate bio-social development: biological, social and ecological determinants (pp. 159-187). New York: Garland Publishing. 
Chevalier-Skolnikoff, S. (1982). A cognitive analysis of facial behavior in Old World monkeys, apes, and human beings. In C. T. Snowdon, C. H. Brown \& M. R. Petersen (Eds.), Primate Communication (pp. 303-368). Cambridge, UK: Cambridge University Press.

Chevalier-Skolnikoff, S. (1983). Sensorimotor development in orang-utans and other primates. Journal of Human Evolution, 12, 545-561.

Chevalier-Skolnikoff, S. (1989). Spontaneous tool use and sensorimotor intelligence in Cebus compared with other monkeys and apes. Behavioral and Brain Sciences, 12, 561-627.

Clark, A. (2011). Supersizing the mind: Embodiment, action and cognitive extension. Oxford: Oxford University Press.

Darwin, C. (1877). A biographical sketch of an infant. Mind, 2, 285-294.

Davidson, G., Miller, R., Loissel, E., Cheke, L. G., \& Clayton, N. S. (2017). The development of support intuitions and object causality in juvenile Eurasian jays (Garrulus glandarius). Scientific Reports, 7, 40062.

DeCasien, A. R., Williams, S. A., \& Higham, J. P. (2017). Primate brain size is predicted by diet but not sociality. Nature Ecology and Evolution, 1, 0112.

Doré, F. Y., \& Dumas, C. (1987). Psychology of animal cognition: Piagetian studies. Psychological Bulletin, 102, 219-233.

dos Reis, M., Thawornwattana, Y., Angelis, K., Telford, M. J., Donoghue, P. C. J., \& Yang, Z. (2015). Uncertainty in the timing of origin of animals and the limits of precision in molecular timescales. Current Biology, 25, 2939-2950.

Dumas, C., \& Doré, F. (1991). Cognitive development in kittens (Felis catus): An observational study of object permanence and sensorimotor intelligence. Journal of Comparative Psychology, 105, 357-365.

Dunning, J. B. (2008). CRC handbook of avian body masses. Boca Raton: CRC Press.

Emery, N. J., \& Clayton, N. S. (2004). The mentality of crows: Convergent evolution of intelligence in corvids and apes. Science, 306, 1903-1907.

Fiset, S., Nadeau-Marchand, P., \& Hall, N. J. (2014). Cognitive development in gray wolves: development of object permanence and sensorimotor intelligence with respect to domestic dogs. In A. Horowitz (Ed.), Domestic dog cognition and behavior: The scientific study of Canis familiaris (pp. 155-174). Berlin: Springer-Verlag.

Fragaszy, D. M. (1989). Tool use, imitation, and insight: Apples, oranges, and conceptual pea soup. Behavioral and Brain Sciences, 12, 596-598.

Fragaszy, D. M. (1990). Early behavioral development in capuchins (Cebus). Folia Primatologica, 54, 119-128.

Fragaszy, D. M., Baer, J., \& Adams-Curtis, L. (1991). Behavioral development and maternal care in tufted capuchins (Cebus apella) and squirrel monkeys (Saimiri sciureus) from birth through seven months. Developmental Psychobiology, 24, 375-393.

Funk, M. S. (1996a). Development of object permanence in the New Zealand parakeet (Cyanoramphus auriceps). Animal Learning \& Behavior, 24, 375-383.

Funk, M. S. (1996b). Spatial skill development in golden-crowned parakeets (Cyanoramphus auriceps): A Piagetian assessment. Bird Behavior, 11, 91-104.

Funk, M. S. (2002). Problem solving skills in young yellow-crowned parakeets (Cyanoramphus auriceps). Animal Cognition, 5, 167-176.

Funk, M. S., \& Matteson, R. (2004). Stable individual differences on developmental tasks in young yellow-crowned parakeets, Cyanoramphus auriceps. Learning \& Behavior, 32, 427-439.

Gabi, M., Collins, C. E., Wong, P., Kaas, J. H., \& Herculano-Houzel, S. (2010). Cellular scaling rules for the brain of an extended number of primate species. Brain, Behavior and Evolution, 76, 32-44.

Garwicz, M., Christensson, M., \& Psouni, E. (2009). A unifying model for timing of walking onset in humans and other mammals. Proceedings of the National Academy of Sciences, 106, 21889-21893.

Gelman, R., \& Baillargeon, R. (1983). A review of some Piagetian concepts. In J. H. Flavell \& E. M. Markman (Eds.), Handbook of child psychology: Cognitive development (pp. 167-230). New York: John Wiley \& Sons.

Gómez, J. C. (2004). Apes, monkeys, children, and the growth of mind. Cambridge, MA: Harvard University Press.

Gould, S. J. (1977). Ontogeny and phylogeny. Cambridge, MA: Belknap Press.

Güntürkün, O., \& Bugnyar, T. (2016). Cognition without cortex. Trends in Cognitive Sciences, 20, 291-303. Güntürkün, O., Stacho, M., \& Ströckens, F. (2017). The brains of reptiles and birds. In J. H. Kaas (Ed.), Evolution of nervous systems (pp. 171-222). Oxford: Academic Press.

Hallock, M. B., \& Worobey, J. (1984). Cognitive development in chimpanzee infants (Pan troglodytes). Journal of Human Evolution, 13, 441-447. 
Heinrich, B. (1995a). An experimental investigation of insight in common ravens (Corvus corax). The Auk, 112, 994-1003.

Heinrich, B. (1995b). Neophilia and exploration in juvenile common ravens, Corvus corax. Animal Behaviour, 50, 695-704.

Heinrich, B. (2011). Conflict, cooperation, and cognition in the common raven. Advances in the Study of Behavior, $43,189-237$.

Herculano-Houzel, S. (2012). The remarkable, yet not extraordinary, human brain as a scaled-up primate brain and its associated cost. Proceedings of the National Academy of Sciences USA, 109, 10661-10668.

Herculano-Houzel, S. (2017). Numbers of neurons as biological correlates of cognitive capability. Current Opinion in Behavioral Sciences, 16, 1-7.

Herculano-Houzel, S. (2018). Longevity and sexual maturity vary across species with number of cortical neurons, and humans are no exception. Journal of Comparative Neurology, 527, 1-17.

Herculano-Houzel, S., Catania, K., Manger, P. R., \& Kaas, J. H. (2015). Mammalian brains are made of these: A dataset of the numbers and densities of neuronal and nonneuronal cells in the brain of Glires, Primates, Scandentia, Eulipotyphlans, Afrotherians and Artiodactyls, and their relationship with body mass. Brain, Behavior and Evolution, 86, 145-163.

Herculano-Houzel, S., Collins, C. E., Wong, P., \& Kaas, J. H. (2007). Cellular scaling rules for primate brains. Proceedings of the National Academy of Sciences USA, 104, 3562-3567.

Herculano-Houzel, S., \& Kaas, J. H. (2011). Gorilla and orangutan brains conform to the primate cellular scaling rules: implications for human evolution. Brain, Behavior and Evolution, 77, 33-44.

Hoffmann, A., Rüttler, V., \& Nieder, A. (2011). Ontogeny of object permanence and object tracking in the carrion crow, Corvus corone. Animal Behaviour, 82, 359-367.

Holekamp, K. E., Swanson, E. M., \& Van Meter, P. E. (2013). Developmental constraints on behavioural flexibility. Philosophical Transactions of the Royal Society B, 368, 20120350.

Jacobs, I. F., \& Osvath, M. (2015). The string-pulling paradigm in comparative psychology. Journal of Comparative Psychology, 129, 89-120.

Jacobs, I. F., Osvath, M., Osvath, H., Mioduszewska, B., von Bayern, A. M., \& Kacelnik, A. (2014). Object caching in corvids: Incidence and significance. Behavioural Processes, 102, 25-32.

Jardim-Messeder, D., Lambert, K., Noctor, S., Pestana, F. M., de Castro Leal, M. E., Bertelsen, M. F., ... Herculano-Houzel, S. (2017). Dogs have the most neurons, though not the largest brain: Trade-off between body mass and number of neurons in the cerebral cortex of large carnivorian species. Frontiers in Neuroanatomy, 11, 118.

Kabadayi, C., Jacobs, I., \& Osvath, M. (2017). The development of motor self-regulation in ravens. Frontiers in Psychology, 8, 2100.

Keijzer, F. A. (2017). Evolutionary convergence and biologically embodied cognition. Interface Focus, 7, 20160123.

Kenward, B., Schloegl, C., Rutz, C., Weir, A. A. S., Bugnyar, T., \& Kacelnik, A. (2011). On the evolutionary and ontogenetic origins of tool-oriented behaviour in New Caledonian crows (Corvus moneduloides). Biological Journal of the Linnean Society, 102, 870-877.

Kondo, N., Izawa, E.-I., \& Watanabe, S. (2012). Crows cross-modally recognize group members but not non-group members. Proceedings of the Royal Society B, 279, 1937-1942.

Lambert, M. L., Jacobs, I., Osvath, M., \& von Bayern, A. M. P. (2019). Birds of a feather? Parrot and corvid cognition compared. Behaviour, 156, 505-594.

Lambert, M. L., Seed, A. M., \& Slocombe, K. E. (2015). A novel form of spontaneous tool use displayed by several captive greater vasa parrots (Coracopsis vasa). Biology Letters, 11, 20150861.

Langer, J. (2006). The heterochronic evolution of primate cognitive development. Biological Theory, 1, 41-43.

Loretto, M.-C., Fraser, O. N., \& Bugnyar, T. (2012). Ontogeny of social relations and coalition formation in common ravens (Corvus corax). International Journal of Comparative Psychology, 25, 180-194.

Lourenço, O. M. (2016). Developmental stages, Piagetian stages in particular: A critical review. New Ideas in Psychology, 40, 123-137.

Lourenço, O. M., \& Machado, A. (1996). In defense of Piaget's theory: A reply to 10 common criticisms. Psychological Review, 103, 143-164.

MacLean, E. L., Matthews, L. J., Hare, B. A., Nunn, C. L., Anderson, R. C., Aureli, F., .. Wobber, V. (2012). How does cognition evolve? Phylogenetic comparative psychology. Animal Cognition, 15, 223-238.

Massen, J. J., Pašukonis, A., Schmidt, J., \& Bugnyar, T. (2014). Ravens notice dominance reversals among conspecifics within and outside their social group. Nature Communications, 5, 3679. 
Mathieu, M., Daudelin, N., Dagenais, Y., \& Décarie, T. G. (1980). Piagetian causality in two house-reared chimpanzees (Pan troglodytes). Canadian Journal of Psychology, 34, 179-186.

Melin, A. D., Young, H. C., Mosdossy, K. N., \& Fedigan, L. M. (2014). Seasonality, extractive foraging and the evolution of primate sensorimotor intelligence. Journal of Human Evolution, 71, 77-86.

Miller, R., Bugnyar, T., Pölzl, K., \& Schwab, C. (2015). Differences in exploration behaviour in common ravens and carrion crows during development and across social context. Behavioral Ecology and Sociobiology, 69, 1209-1220.

Miller, R., Laskowski, K. L., Schiestl, M., Bugnyar, T., \& Schwab, C. (2016). Socially driven consistent behavioural differences during development in common ravens and carrion crows. PloS ONE, 11, e0148822.

Miller, R., Schwab, C., \& Bugnyar, T. (2016). Explorative innovators and flexible use of social information in common ravens (Corvus corax) and carrion crows (Corvus corone). Journal of Comparative Psychology, $130,328-340$.

Mills, W. (1898). The nature and development of animal intelligence. New York: Macmillan.

Morgan, C. L. (1896). Habit and instinct. London: Edward Arnold.

Müller, U. (2009). Infancy. In U. Müller, J. I. M. Carpendale \& L. Smith (Eds.), The Cambridge companion to Piaget (pp. 200-228). Cambridge: Cambridge University Press.

Olkowicz, S., Kocourek, M., Lučan, R. K., Porteš, M., Fitch, W. T., Herculano-Houzel, S., \& Němec, P. (2016). Birds have primate-like numbers of neurons in the forebrain. Proceedings of the National Academy of Sciences, 113, 7255-7260.

Osvath, M., Kabadayi, C., \& Jacobs, I. F. (2014a). Independent evolution of similar complex cognitive skills: The importance of embodied degrees of freedom. Animal Behavior and Cognition, 1, 249-264.

Osvath, M., Osvath, H., \& Bååth, R. (2014). An exploration of play behaviors in raven nestlings. Animal Behavior and Cognition, 1, 157-165.

Padberg, J., Franca, J. G., Cooke, D. F., Soares, J. G., Rosa, M. G., Fiorani, M., ... Krubitzer, L. (2007). Parallel evolution of cortical areas involved in skilled hand use. Journal of Neuroscience, 27, 10106-10115.

Parker, S. T. (1977). Piaget's sensorimotor series in an infant macaque: A model for comparing unstereotyped behavior and intelligence in human and nonhuman primates. In S. Chevalier-Skolnikoff \& F. E. Poirier (Eds.), Primate bio-social development: Biological, social and ecological determinants (pp. 43-112). New York: Garland Publishing.

Parker, S. T., \& Gibson, K. R. (1977). Object manipulation, tool use and sensorimotor intelligence as feeding adaptations in Cebus monkeys and great apes. Journal of Human Evolution, 6, 623-641.

Parker, S. T., \& Gibson, K. R. (1979). A developmental model for the evolution of language and intelligence in early hominids. Behavioral and Brain Sciences, 2, 367-381.

Parker, S. T., \& McKinney, M. L. (1999). Origins of intelligence: The evolution of cognitive development in monkeys, apes, and humans. London: John Hopkins University Press.

Pepperberg, I. M. (2002). The value of the Piagetian framework for comparative cognitive studies. Animal Cognition, 5, 177-182.

Pepperberg, I. M., Willner, M. R., \& Gravitz, L. B. (1997). Development of Piagetian object permanence in a grey parrot (Psittacus erithacus). Journal of Comparative Psychology, 111, 63-75. Piaget, J. (1951). Play, dreams and imitation in childhood. London: Routledge.

Piaget, J. (1952). The origins of intelligence in children. New York: Norton.

Piaget, J. (1954). The construction of reality in the child. New York: Basic Books.

Pollok, B., Prior, H., \& Güntürkün, O. (2000). Development of object permanence in food-storing magpies (Pica pica). Journal of Comparative Psychology, 114, 148-157.

Potí, P. (1989). Early sensorimotor development in macaques. In F. Antinucci (Ed.), Cognitive structure and development in nonhuman primates (pp. 39-54). Hillsdale: Lawrence Erlbaum Associates.

Potí, P., \& Spinozzi, G. (1994). Early sensorimotor development in chimpanzees (Pan troglodytes). Journal of Comparative Psychology, 108, 93-103.

Redshaw, M. (1978). Cognitive developments in human and gorilla infants. Journal of Human Evolution, 7, 133141.

Rosati, A. G., Wobber, V., Hughes, K., \& Santos, L. R. (2014). Comparative developmental psychology: How is human cognitive development unique? Evolutionary Psychology, 12, 448-473.

Rutz, C., Klump, B. C., Komarczyk, L., Leighton, R., Kramer, J., Wischnewski, S., ... Masuda, B. M. (2016). Discovery of species-wide tool use in the Hawaiian crow. Nature, 537, 403-407. 
Salwiczek, L. H., Emery, N. J., Schlinger, B., \& Clayton, N. S. (2009). The development of caching and object permanence in western scrub-jays (Aphelocoma californica): Which emerges first? Journal of Comparative Psychology, 123, 295-303.

Sayol, F., Lefebvre, L., \& Sol, D. (2016). Relative brain size and its relation with the associative pallium in birds. Brain, Behavior and Evolution, 87, 69-77.

Schloegl, C., Kotrschal, K., \& Bugnyar, T. (2007). Gaze following in common ravens, Corvus corax: Ontogeny and habituation. Animal Behaviour, 74, 769-778.

Spelke, E. S. (1991). Physical knowledge in infancy: Reflections on Piaget's theory. In S. Carey \& R. Gelman (Eds.), The epigenesis of mind: essays on biology and cognition (pp. 133-170). Hillsdale, NJ: Lawrence Erlbaum Associates.

Spinozzi, G. (1989). Early sensorimotor development in Cebus. In F. Antinucci (Ed.), Cognitive structure and development in nonhuman primates (pp. 55-66). Hillsdale, NJ: Lawrence Erlbaum Associates.

Spinozzi, G., \& Natale, F. (1989). Early sensorimotor development in Gorilla. In F. Antinucci (Ed.), Cognitive structure and development in nonhuman primates (pp. 21-38). Hillsdale, NJ: Lawrence Erlbaum Associates.

Stöwe, M., Bugnyar, T., Loretto, M.-C., Schloegl, C., Range, F., \& Kotrschal, A. (2006). Novel object exploration in ravens (Corvus corax): Effects of social relationships. Behavioural Processes, 73, 68-75.

Stöwe, M., Bugnyar, T., Schloegl, C., Heinrich, B., Kotrschal, K., \& Möstl, E. (2008). Corticosterone excretion patterns and affiliative behavior over development in ravens (Corvus corax). Hormones and Behavior, 53, 208-216.

Thelen, E., Schoner, G., Scheier, C., \& Smith, L. B. (2001). The dynamics of embodiment: A field theory of infant perseverative reaching. Behavioral and Brain Sciences, 24, 1-86.

Tinbergen, N. (1963). On aims and methods of ethology. Zeitschrift für Tierpsychologie, 20, 410-433.

Ujfalussy, D., Miklósi, Á., \& Bugnyar, T. (2013). Ontogeny of object permanence in a non-storing corvid species, the jackdaw (Corvus monedula). Animal Cognition, 16, 405-416.

Užgiris, I. C̆., \& Hunt, J. M. (1975). Assessment in infancy: Ordinal scales of psychological development. Chicago: University of Illinois Press.

Vallortigara, G. (2012a). The cognitive chicken: Visual and spatial cognition in a non-mammalian brain. In T. R. Zentall \& E. A. Wasserman (Eds.), The Oxford handbook of comparative cognition (pp. 48-66). Oxford: Oxford University Press.

Vallortigara, G. (2012b). Core knowledge of object, number, and geometry: A comparative and neural approach. Cognitive Neuropsychology, 29, 213-236.

van Horik, J. O., Clayton, N. S., \& Emery, N. J. (2012). Convergent evolution of cognition in corvids, apes and other animals. In J. Vonk \& T. K. Shackelford (Eds.), The Oxford handbook of comparative evolutionary psychology (pp. 80-101). Oxford: Oxford University Press.

Vauclair, J. (2012). Piaget and the comparative psychology of animal cognition. In E. Martí \& C. Rodríguez (Eds.), After Piaget (pp. 59-70). New Brunswick, NJ: Transaction.

West-Eberhard, M. J. (2003). Developmental plasticity and evolution. Oxford: Oxford University Press.

Wilson, M. (2002). Six views of embodied cognition. Psychonomic Bulletin \& Review, 9, 625-636.

Winters, S., Dubuc, C., \& Higham, J. P. (2015). The looking time experimental paradigm in studies of animal visual perception and cognition. Ethology, 121, 625-640.

Wobber, V., Herrmann, E., Hare, B., Wrangham, R., \& Tomasello, M. (2014). Differences in the early cognitive development of children and great apes. Developmental Psychobiology, 56, 547-573.

Zucca, P., Milos, N., \& Vallortigara, G. (2007). Piagetian object permanence and its development in Eurasian jays (Garrulus glandarius). Animal Cognition, 10, 243-258. 